\title{
Characteristics of aerosol particle size distributions in urban Lanzhou, north-western China
}

\author{
Y. Yu ${ }^{1}$, S. P. Zhao ${ }^{1,2}$, D. S. Xia ${ }^{1}$, J. J. He ${ }^{1,2}$, N. Liu ${ }^{1,2}$ \& J. B. Chen ${ }^{1}$ \\ ${ }^{I}$ Key Laboratory of Land Surface Process and Climate Change in Cold \\ and Arid Regions, Cold \& Arid Regions Environmental \& Engineering \\ Research Institute, CAS, Lanzhou, Gansu, China \\ ${ }^{2}$ Graduate School of the Chinese Academy of Sciences, Beijing, China
}

\begin{abstract}
Continuous particle size data $(0.5-20 \mu \mathrm{m})$ were collected using aerodynamic particle sizer (TSI 3321) at an urban site in Lanzhou, north western China from $1^{\text {st }}$ August to $31^{\text {st }}$ October. Variations of particle concentrations and general characteristics of particle size distributions were analyzed. The hourly averaged particle number, surface area and volume concentration are $108.1 \pm 92.2 \mathrm{~cm}^{-3}, 282.9 \pm 267.9 \mu \mathrm{m}^{2} \mathrm{~cm}^{-3}$ and $92.2 \pm 127.3 \mu \mathrm{g}^{3} \mathrm{~m}^{-3}$, respectively. Fine particles $(0.5-2.5 \mu \mathrm{m})$ accounted for $98.7 \%, 73.8 \%$ and $37.5 \%$ of the total particle number, surface area and volume concentrations in $0.5-20 \mu \mathrm{m}$, respectively. The size distribution of number concentrations is unimodal with a maximum at $0.54-0.58 \mu \mathrm{m}$, while that of the surface area and volume concentrations are bimodal. The main peak of surface area concentration appears near $0.63-0.67 \mu \mathrm{m}$ with a secondary peak at $3.79-4.07 \mu \mathrm{m}$, and the main peak of volume concentration is at $4.7-5.1 \mu \mathrm{m}$ with a secondary peak near $0.67-0.72 \mu \mathrm{m}$. $\mathrm{K}$-means cluster analysis was used to group the particle volume size distributions into 7 clusters by their dominant mode and average concentration. Particle volume size distributions observed during dust storms and under dry and clear weather conditions were characterized by a single coarse mode, while particle volume size distributions affected by fog, smog and traffic related emissions were bimodal with peaks at accumulation mode and coarse mode, respectively.
\end{abstract}

Keywords: air pollution, size distribution, aerosols particles, volume concentration, meteorological condition. 


\section{Introduction}

Atmospheric aerosol particles play an important role in climate change, [1]. They also have a determining effect on visibility, [2] and human health, [3]. Several studies have indicated the dependence of the direct and indirect climate effects, the health effect and environmental effect of the atmospheric aerosols on particle properties, such as size distributions, [4, 5]. Knowledge of the properties and the factors affecting particle size distributions is thus important not only for understanding aerosol formation mechanisms and improving the parameterisation in climate models, but also for identifying the sources. In recent years, many studies have been done on urban particle size distributions. However, most of the studies were carried out in the European and North American cities, $[6,7]$. In China, most of the studies were conducted in central eastern or coastal areas, [8-10]. Studies in north western China were mainly concentrated on particulate mass, with little or no information on size distributions, [13], especially for urban areas.

Lanzhou, the capital of Gansu Province, has an urban population of about 2.6 million and a total population of 3.6 million in 2010, [11] and is one of the most polluted cities in China, [12]. Like many cities in northern China, particulate matter is one of the most formidable air quality and public health issues in Lanzhou. Actions toward reducing emissions of aerosol particles have being put into effect, but the levels of particulate pollution remain high. $\mathrm{Yu}$ [13] showed that annual mean mass concentration of $\mathrm{PM}_{10}$ in urban Lanzhou has decreased from $236 \mu \mathrm{gm}^{-3}$ in 2001 to $127 \mu \mathrm{gm}^{-3}$ in 2007 , but still exceed the national Grade II standard for annual mean $\mathrm{PM}_{10}$ concentration $\left(100 \mu \mathrm{gm}^{-3}\right)$ by $27 \%$.

There have been several studies about particulate pollution in Lanzhou: Wei et al. [14] analyzed the $\mathrm{PM}_{2.5}$ and $\mathrm{PM}_{10}$ in four Chinese cities including Lanzhou, with emphasis on the elements' size distributions; Wang et al. [15] reported the mass concentrations of $\mathrm{PM}_{2.5}$ and $\mathrm{PM}_{10}$ and their annual and diurnal variations; Wang et al. [16] reported particle mass size distributions for $\mathrm{PM}_{10}$ under different weather conditions, but with rather coarse resolution. Previous measurement of atmospheric particle size distributions in Lanzhou urban area have been scarce, and generally been conducted only for a short period, until now the knowledge of the aerosol particle size distributions in Lanzhou urban area is very limited. In order to better understand the particulate pollution in Lanzhou and establish effective control strategies, continuous measurements of particle size distributions in the range of $0.5-20 \mu \mathrm{m}$ are reported in this paper, with the intention of understanding the characteristics of atmospheric particle size distributions and their affecting factors.

\section{Method}

\subsection{Sampling site}

Lanzhou $\left(36.1^{\circ} \mathrm{N}, 103.8^{\circ} \mathrm{E}\right)$ is situated at the intersection of Qinghai-Tibet Plateau, the Inner Mongolian Plateau and the Loess Plateau. It is surrounded by 
mountains and hills that rise to $500-600 \mathrm{~m}$. Fig. 1 shows the topography of Lanzhou and the location of the sampling site. The sampling site was on the roof of an academic building of the Cold \& Arid Regions Environmental \& Engineering Institute (CAREEI), located in the eastern part of Lanzhou urban area. The inlet of sampling system was about $32 \mathrm{~m}$ above the ground level. The site is a primarily residential and commercial area without obvious industrial sources. There are two major roads with heavy traffic, i.e. Donggang West Road and Tianshui road, at the south and the west of the sampling site, with a distance of about $40 \mathrm{~m}$ and $300 \mathrm{~m}$ from the sampling site, respectively.

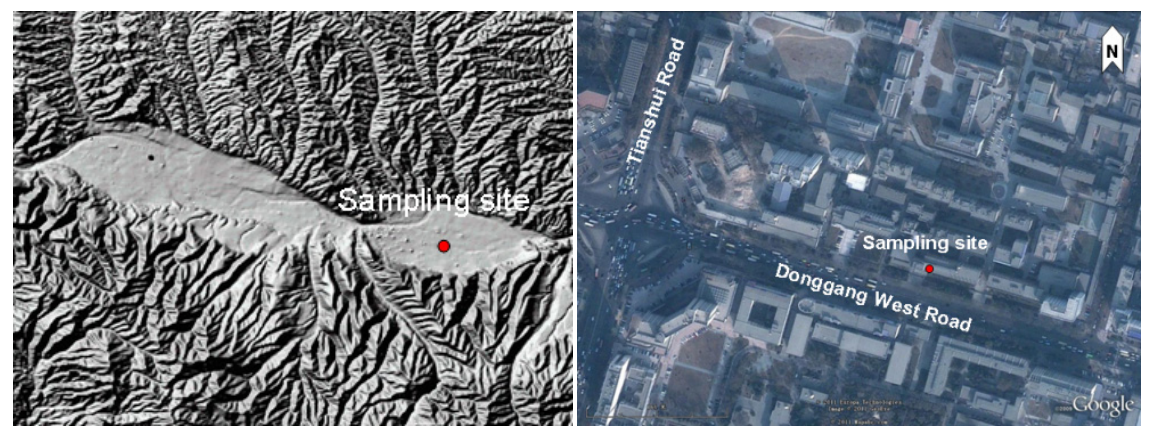

Figure 1: The topographic map of Lanzhou and location of the sampling site.

\subsection{Measurement}

Aerosol size distribution between 0.5 and $20 \mu \mathrm{m}$ in particle aerodynamic diameter was continuously measured during $1^{\text {st }}$ August and 31 October using an aerodynamic particle sizer (APS, TSI model 3321). The flow rate of APS is 1L $\mathrm{min}^{-1}$ with a sheath air flow rate of $4 \mathrm{Lmin}^{-1}$. The time resolution is $5 \mathrm{~min}$ per scan. Flow rate checks were made once a week with a bubble flow meter.

Meteorological data were obtained from an automatic meteorological station co-located with the sampling site. Weather observations from a weather station $1.7 \mathrm{~km}$ from the site were also used. The observation period covered the end of summer and the autumn of Lanzhou. East and northeast wind prevailed during the observation period.

\subsection{Data processing}

Hourly average size distributions were calculated from the original data. To be included in the subsequent analysis, each average value must consist of at least half hour's data. After data screening, a total of 2082 hourly particle size distributions were left. Cluster analysis was used to reduce the number of hourly volume size distributions into several groups with similar characteristics. The Kmeans clustering routine available in MATLABC was used in this study. The Kmeans clustering routine split the existing multidimensional data into predefined 
number of subgroups, i.e. clusters, which are as different as possible from each other, but as homogeneous as possible within themselves, by iteratively minimizing the sum of squared Euclidean distances from each member to its cluster centroid. The K-means clustering method has been used in various studies and been justified as a preferred technique for particle size distribution data analysis, [17]. In this study we limited the analysis to include 7 clusters. Different number of clusters was tested and it is found that increasing the number of clusters above seven did not provide more information, while decreasing the number of clusters below seven lost information on some well characterized size distributions.

\section{Results and discussion}

The aerosol particle size distributions were integrated to calculate particle number, surface area and volume concentrations in different size ranges. In this study, particles in the diameter from 0.5 to $20 \mu \mathrm{m}$ were divided into three subranges: $0.5-1.0 \mu \mathrm{m}, 1.0-2.5 \mu \mathrm{m}$, and $2.5-10 \mu \mathrm{m}$. The total particle concentrations refer to particle concentrations within $0.5-20 \mu \mathrm{m}$. The particle surface area and volume concentrations were calculated from the measured number size distributions with an assumption of spherical particles.

\subsection{Particle concentrations}

Table 1 summarizes the statistics for hourly averaged particle number, surface area, and volume concentrations for different size ranges covering the observation period. The total particle number, surface area, and volume concentrations are $108.1 \pm 92.2 \mathrm{~cm}^{-3}, \quad 282.9 \pm 267.9 \mu \mathrm{m}^{2} \mathrm{~cm}^{-3}, \quad$ and $92.2 \pm 127.3 \mu \mathrm{m}^{3} \mathrm{~cm}^{-3}$, respectively. The total number and surface area concentrations are dominated by fine particles $(0.5-2.5 \mu \mathrm{m})$, which account for $98.7 \%$ and $73.8 \%$ of the corresponding total concentrations. $62.5 \%$ of the total volume concentration was contributed by coarse particles $(2.5-20 \mu \mathrm{m})$. The particle number concentrations in size ranges $0.5-1.0 \mu \mathrm{m}, 1.0-2.5 \mu \mathrm{m}$, and 2.5 $10 \mu \mathrm{m}$ are $98.1 \mathrm{~cm}^{-3}, 8.5 \mathrm{~cm}^{-3}$, and $1.5 \mathrm{~cm}^{-3}$, respectively, and $90.8 \%$ of the particle numbers are in $0.5-1.0 \mu \mathrm{m}$. When aerosol particle concentrations in this study are compared with other studies in Chinese urban areas, it is noticed that the average number concentration in size range $0.5-1.0 \mu \mathrm{m}$ in Lanzhou is close to the values observed in spring of Guangzhou, [18] and in summer of Ji'nan urban areas, [19], while the number concentration in size range $2.5-20 \mu \mathrm{m}$ is higher than that observed in Guangzhou and lower than that observed in winter of Beijing $\left(3.4 \mathrm{~cm}^{-1}\right)$, [20] and in winter and summer of Shenyang $\left(4.4 \mathrm{~cm}^{-1}\right)$, [21] urban areas. In addition to differences in local sources, the influence of surrounding arid and semi-arid areas may lead to a background with relatively higher coarse particles in Lanzhou. 
Table 1: $\quad$ Statistics of hourly averaged particle concentration for different size ranges during 1st August-31st October 2010.

\begin{tabular}{cccccc}
\hline & $\begin{array}{c}\text { Size range } \\
(\mu \mathrm{m})\end{array}$ & Mean \pm Std & Max. & Min. & $\begin{array}{c}\text { Percentage of the } \\
\text { total concentration } \\
(\%)\end{array}$ \\
\hline Number & $0.5-1.0$ & $98.1 \pm 86.6$ & 586.8 & 4.0 & 90.8 \\
$\begin{array}{c}\text { concentration } \\
\left(/ \mathrm{cm}^{3}\right)\end{array}$ & $1.0-2.5$ & $8.5 \pm 10.1$ & 97.2 & 0.1 & 7.9 \\
\hline Surface area & $2.5-10$ & $1.5 \pm 2.7$ & 32.2 & $<0.1$ & 1.4 \\
concentration & $0.5-20$ & $108.1 \pm 92.2$ & 627.4 & 4.1 & 100.0 \\
$\left(\mu \mathrm{m}^{2} / \mathrm{cm}^{3}\right)$ & $1.0-2.5$ & $59.9 \pm 77.0$ & 786.7 & 0.6 & 52.6 \\
\hline $\mathrm{Volume}_{\text {concentration }}$ & $0.5-10$ & $73.4 \pm 134.1$ & 1672.2 & 0.1 & 21.2 \\
$\left(\mu \mathrm{m}^{3} / \mathrm{cm}^{3}\right)$ & $0.5-1.0$ & $282.9 \pm 267.9$ & 2621.5 & 7.0 & 26.0 \\
\hline
\end{tabular}

\subsection{Average particle size distributions}

The average particle number, surface area and volume size distributions during the observation period are shown in fig. 2. The maximum of the number size distribution appear at $0.54-0.58 \mu \mathrm{m}$. The surface area and volume size distributions contain two predominant modes at $0.63-0.67 \mu \mathrm{m}$ and $3.79-4.07 \mu \mathrm{m}$, and at $4.70-5.05 \mu \mathrm{m}$ and $0.67-0.72 \mu \mathrm{m}$, respectively. Fine particles with diameter below $2.5 \mu \mathrm{m}$, accounting for $98.7 \%$ of the total particle numbers, were the main contributor to the total particle number concentrations, while coarse particles were the main contributor to the total volume concentrations. The coarse mode in our study (at 4.70-5.05 $\mu \mathrm{m}$ ) appeared at a larger particle size than that for urbaninfluenced aerosols (at 3-4 $\mu \mathrm{m}$ ) studied by Morawska et al. [22], indicating the possible effect of the arid and semi-arid background, [23].

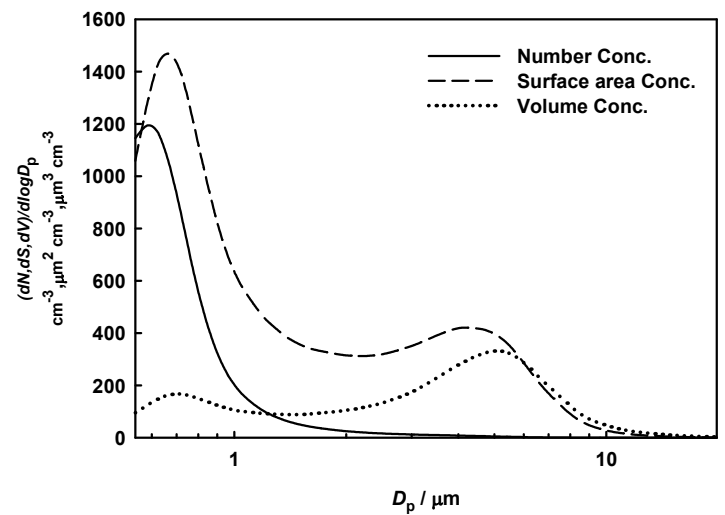

Figure 2: $\quad$ Size distribution of mean particle number, surface area and volume concentrations during the observation period. 


\subsection{Clusters of volume size distributions}

The volume size distribution data were grouped into seven distinctly separated clusters, which are referred to as A to $\mathrm{G}$ and shown in fig. 3. The statistical description of the seven clusters and the corresponding meteorological conditions are summarized in table 2 .

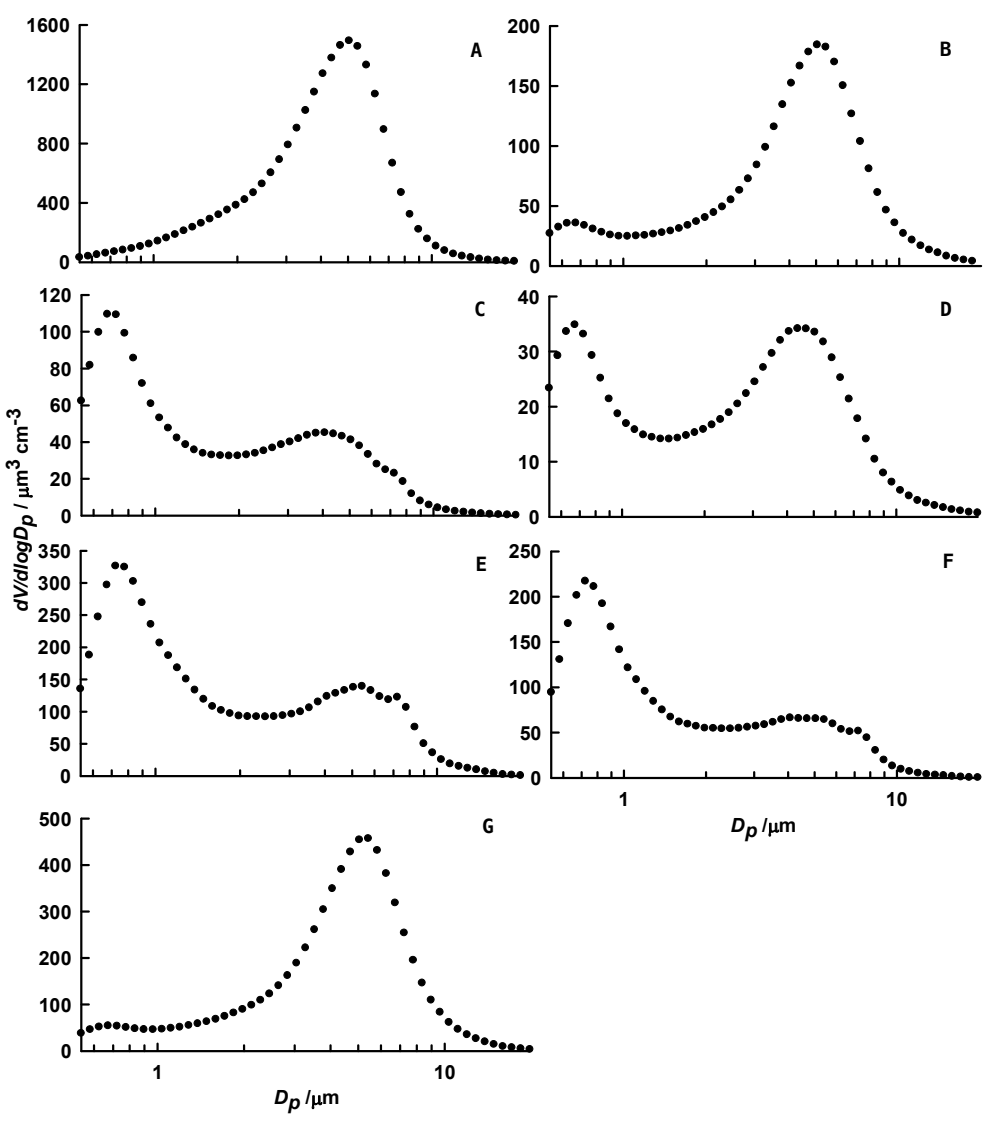

Figure 3: Average volume size distributions for clusters A to G.

Clusters A, B and G show a similar shaped coarse mode at $4.70-5.42 \mu \mathrm{m}$, with clusters $B$ and $G$ having another small peak at the accumulation mode. Cluster A contains only 61 particle volume size distributions (2.9\%). The total particle $(0.5-20 \mu \mathrm{m})$ volume, number and surface area concentrations of cluster A are the highest among the seven clusters, with coarse particles contributing $78 \%$ to its total volume concentration. Cluster A was exclusively observed in August and experienced the highest wind speed and temperature among the seven clusters. Lanzhou was affected by an exceptional dust storm during 12-13 August 2010 (dust storms generally occur during springtime, i.e. March, April 
and March) and most of the size distributions in cluster A were observed during the dust storm. Thus cluster A represents the volume size distributions affect by dust storms. A total of $17.9 \%$ and $8.3 \%$ of the volume size distributions belong to clusters B and G, respectively. Fig. 4 shows the diurnal variation of the hourly ratio of the number counts of a cluster to the hourly total count of all the clusters. There is no preferred time in a day for the occurrence of cluster B. Cluster B was related to the driest meteorological conditions among the seven clusters and had relatively high wind speed and temperature. The total particle volume, number and surface area concentrations of cluster B are the lowest among the three clusters dominated by coarse mode. Cluster B represents the volume size distributions observed under dry, clear and good dispersion conditions. The hourly ratio of the number counts of cluster G (fig. 4) shows that the cluster occurred most frequently from midnight till noon, corresponding well to the diurnal variation of wind speed, i.e. low wind speed during night and morning hours and high wind speed in the afternoon. The total particle volume, number and surface area concentrations of cluster $G$ is the second highest among the seven clusters. The above analysis indicate that cluster $\mathrm{G}$ represents the volume size distributions observed in general polluted conditions when wind speed was low and the atmosphere was stable.

Table 2: $\quad$ Volume, surface area and number concentrations associated with each cluster, and their corresponding meteorological conditions.

\begin{tabular}{cccccccc}
\hline Clusters & $\mathrm{A}$ & $\mathrm{B}$ & $\mathrm{C}$ & $\mathrm{D}$ & $\mathrm{E}$ & $\mathrm{F}$ & $\mathrm{G}$ \\
\hline $\begin{array}{c}\text { Frequency of } \\
\text { occurrence }(\%)\end{array}$ & 2.9 & 17.9 & 21.5 & 40.1 & 2.8 & 6.4 & 8.3 \\
$\begin{array}{c}\text { Mean Volume } \\
\left(\mu \mathrm{m}^{3} / \mathrm{cm}^{3}\right)\end{array}$ & 714.6 & 97.2 & 61.8 & 30.1 & 196.6 & 113.7 & 220.5 \\
$\begin{array}{c}\text { Mean surface area } \\
\left(\mu \mathrm{m}^{2} / \mathrm{cm}^{3}\right)\end{array}$ & 1591.6 & 250.4 & 348.3 & 131.7 & 1013.6 & 639.8 & 522.0 \\
$\begin{array}{c}\text { Mean Number } \\
\left(\mathrm{cm}^{-3}\right)\end{array}$ & 1088 & 186.6 & 339.6 & 123.5 & 840.3 & 556.5 & 403.3 \\
$\begin{array}{c}\text { Temperature }\left({ }^{\circ} \mathrm{C}\right) \\
\text { Wind speed }(\mathrm{m} / \mathrm{s})\end{array}$ & 22.2 & 21.6 & 14.1 & 18.8 & 8.7 & 10.1 & 20.8 \\
$\begin{array}{c}\text { Relative humidity } \\
(\%)\end{array}$ & 66.6 & 48.6 & 58.0 & 52.2 & 65.8 & 61.5 & 60.2 \\
\hline
\end{tabular}

Cluster D is the most frequently observed cluster type, with $40.1 \%$ of size distributions belong to it. The cluster is characterized by two modes with comparable amplitude: an accumulation mode at $0.63-0.67 \mu \mathrm{m}$ and a coarse mode at $4.07-4.37 \mu \mathrm{m}$. Cluster $\mathrm{D}$ had the lowest total volume concentration $\left(30.1 \mu^{3} \mathrm{~cm}^{-3}\right)$ as well as the lowest total surface area and number concentrations. The average wind speed related to cluster $\mathrm{D}$ was the second highest among the seven clusters (table 2), indicating good dispersion condition. Cluster D also showed a strong dependency on the occurrence of rain, with $54.5 \%$ of size distributions been observed on days with precipitation. The hourly ratio of the number counts of cluster D (fig. 4, middle) has high values during the afternoon 

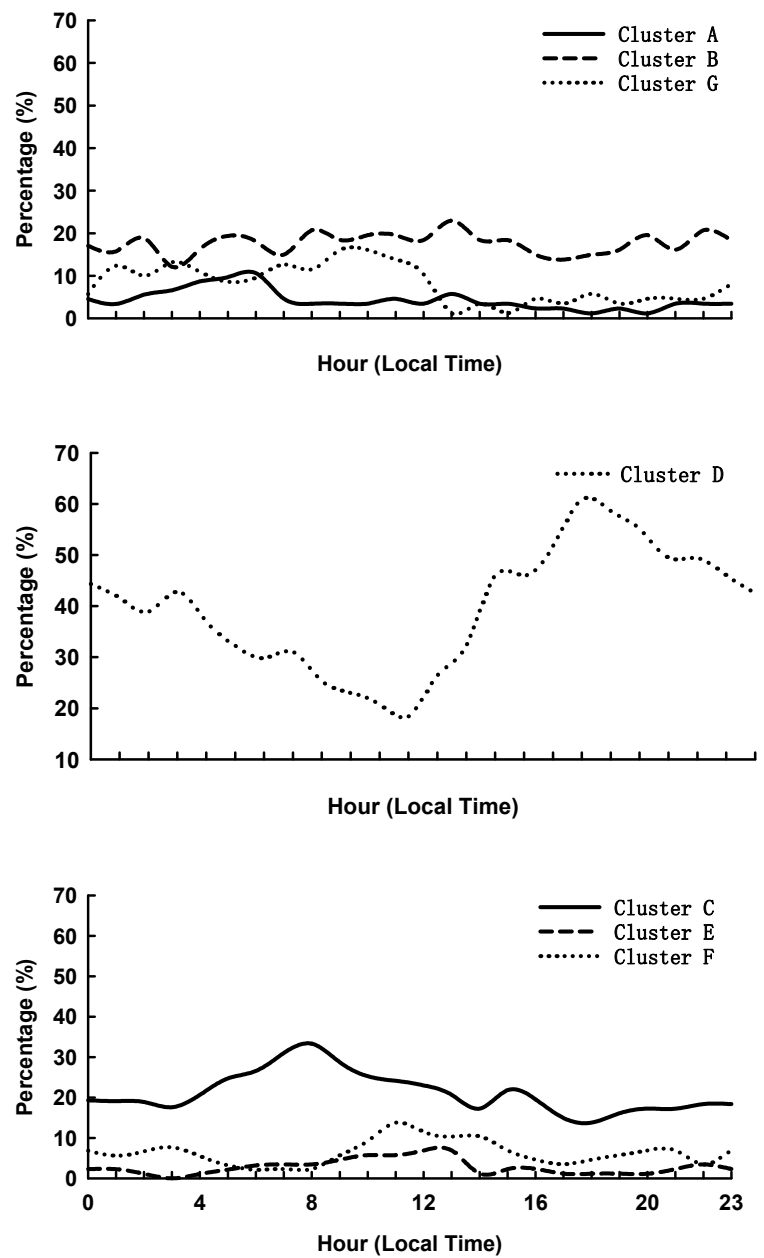

Figure 4: Hourly ratio of the number counts of a cluster (A-G) to the hourly total count of all the clusters calculated as $\mathrm{Ni} / \sum_{i=1}^{7} N_{i}$ given in $\%$.

and evening when the frequency of rain events is high and the wind speed is relatively high. Thus cluster $\mathrm{D}$, which could be regarded as a clean background for the observation site, represents the volume size distributions observed under clean and good dispersion conditions.

Clusters $\mathrm{C}, \mathrm{E}$ and $\mathrm{F}$ have bimodal distributions, with a major mode at 0.63 $0.67 \mu \mathrm{m}$ and a secondary mode at $3.79-4.07 \mu \mathrm{m}$ (clusters $\mathrm{C}$ and F) or $5.05-5.43 \mu \mathrm{m}$ (cluster E). The three clusters are dominated by fine particles, with fine particles accounting for $68 \%, 66 \%$ and $72 \%$ of the average total volume concentrations of 
clusters $\mathrm{C}, \mathrm{E}$ and $\mathrm{F}$, respectively. Cluster $\mathrm{C}$ is second frequent cluster type, with $21.5 \%$ of the size distributions belong to it. Clusters $\mathrm{E}$ and $\mathrm{F}$ occurred much less frequently compared to cluster $\mathrm{C}$, accounting for $2.8 \%$ and $6.4 \%$ of the total size distributions, respectively. Of the three clusters, cluster $\mathrm{C}$ has the lowest mean volume concentration (the second lowest among the seven clusters), while cluster $\mathrm{E}$ has the highest mean volume concentration. It is inferred from fig. 4 that particle volume size distributions within cluster $\mathrm{C}$ were observed most frequently in the early morning when calm conditions prevailed, i.e. local emissions tended to be trapped in the atmospheric boundary layer. There is also a bump of high values at around 15:00 LT, which matches with the time when wind mostly came from the south, southeast and southwest at the observation site, indicating the influence of traffic-related emissions. Thus cluster $\mathrm{C}$ represents the volume size distributions affected by local sources, mainly trafficrelated emissions (e.g. combustion and resuspended dust). A close inspection of the weather observation data at a weather station about $1.7 \mathrm{~km}$ east of the observation site reveal that the particle volume size distributions within clusters $\mathrm{E}$ and $\mathrm{F}$ were associated with the occurrence of fog and smog, respectively. Both clusters $\mathrm{E}$ and $\mathrm{F}$ were related to the lowest average wind speed and temperature and a relatively high relative humidity when compared to other clusters, indicating cold and stable weather conditions.

\section{Conclusions}

Aerosol particle size distributions were measured from $1^{\text {st }}$ August to $31^{\text {st }}$ October 2010 at an urban site in Lanzhou, north-western China with APS. The measurements covered the size range from 0.5 to $20 \mu \mathrm{m}$. The characteristics of the particle concentrations were investigated by dividing the particles into three sub-ranges: $0.5-1.0 \mu \mathrm{m}, 1.0-2.5 \mu \mathrm{m}$, and $2.5-10 \mu \mathrm{m}$. During the observation period, the total particle number, surface area and volume concentrations $(0.5-20 \mu \mathrm{m})$ were $108.1 \pm 92.2 \mathrm{~cm}^{-3}, 282.9 \pm 267.9 \mu \mathrm{m}^{2} \mathrm{~cm}^{-3}$ and $92.2 \pm 127.3 \mu \mathrm{g}^{3} \mathrm{~m}^{-3}$, respectively. The particle number size distributions are unimodal, while the corresponding surface area and volume concentrations are bimodal. The total number and surface area concentrations were dominated by fine particles $(0.5-2.5 \mu \mathrm{m})$, while coarse particles $(2.5-20 \mu \mathrm{m})$ were the main contributor to the total volume concentration. Compared with urban areas near coast, Lanzhou has higher coarse particles due to its arid and semiarid environment.

K-means clustering analysis resulted in seven well separated clusters of the volume size distributions that were different in their dominant mode and average concentrations. The responsible processes for the different clusters were inferred according to the cluster characteristics and relationship to concurrently measured meteorological conditions. The meteorology was found to exert a high influence on the shape of particle volume size distributions. The cluster containing volume size distributions affected by dust storms had a single coarse mode and the highest volume concentration. Under low wind speed and stable conditions, e.g. early morning or night, the volume size distributions of the cluster were dominated by coarse mode and the volume concentration is the second highest. 
The size distributions in the cleanest cluster were mostly observed on days with precipitation and had two modes, at $0.63-0.67 \mu \mathrm{m}$ and $4.07-4.37 \mu \mathrm{m}$, respectively, with comparable amplitude. Bimodal clusters dominated by accumulation mode were generally observed on days with fog or smog.

This study showed the size resolved characteristics of aerosol particles in an urban area, north-western China and the possible effect of meteorological conditions on volume size distributions. However, in order to characterize the size distribution and interactions between meteorology and aerosol physics, a full spectral covering nano-particle and a long-term measurement are needed.

\section{Acknowledgements}

This research is funded by the Chinese Academy of Sciences through the ' 100 Talent Project' and the National Natural Science Foundation of China (41071125).

\section{References}

[1] Haywood, J. M. \& Boucher, O., Estimates of the direct and indirect radiative forcing due to tropospheric aerosols: A review. Reviews of Geophysics, 38, pp. 513-543, 2000.

[2] See, S. W., Balasubramanian, R. \& Wang, W., A study of the physical, chemical, and optical properties of ambient aerosol particles in Southeast Asia during hazy and nonhazy days. Journal of Geophysical Research, 111, D10S08, doi: 10.1029/2005JD0061, 2006.

[3] Dockery, D.W. \& Pope, C.A., Acute respiratory effects of particulate air pollution. Annual Review of Public Health, 15, pp. 107-132, 1994.

[4] Dusek, U., Frank, G. P., Hildebrandt, L., Curtius, J., Schneider, J., Walter, S., Chand, D., Drewnick, F., Hings, S., Jung, D., Borrmann, S. \& Andreae, M. O., Size matters more than chemistry for cloud-nucleating ability of aerosol particles. Science, 312, pp. 1375-1378, 2006.

[5] Nel, A., Air pollution-related illness: effect of particles. Science, 308, pp. 804-806, 2005.

[6] Hussein, T., Puustinen, A., Aalto, P. P., Mäkelä, J. M., Hämeri, K. \& Kulmala, M., Urban aerosol number size distributions. Atmospheric Chemistry \& Physics, 4, pp. 391-411, 2004.

[7] Tunved, P., Nilsson, E. D., Hansson, H.-C. \& Ström, J., Aerosol characteristics of air masses in northern Europe: Influences of location, transport, sinks, and sources. Journal of geophysical research, 110, D07201, doi: 10.1029/2004JD005085, 2005.

[8] Wu, Z.J., Hu, M., Lin, P., Liu, S., Wehner, B. \& Wiedensohler, A., Particle number size distribution in the urban atmosphere of Beijing, China. Atmospheric Environment, 42, pp. 7967-7980, 2008.

[9] Yue, D. L., Hu, M., Wu, Z. J., Guo, S., Wen, M. T., Nowak, A.,Wehner, B., Wiedensohler, A., Takegawa, N., Kondo, Y., Wang, X. S., Li, Y. P., Zeng, L. M. \& Zhang, Y. H., Variation of particle number size 
distributions and chemical compositions at the urban and downwind regional sites in the Pearl River Delta during summertime pollution episodes. Atmospheric Chemistry \& Physics, 10, pp. 9431-9439, 2010.

[10] Gao, J., Wang, T., Zhou, A.H., Wu, W.S. \& Wang, W.X., Measurement of aerosol number size distributions in the Yangtze River delta in China: Formation and growth of particles under polluted conditions. Atmospheric Environment, 43, pp. 829-836, 2009.

[11] 2010 China's Sixth National population census data bulletin for Lanzhou, http://www.lzstats.gov.cn/newsshow.asp?id=2760

[12] Zhang, L., Chen, C.H. \& Murlis, J., Study on winter air pollution control in Lanzhou, China. Water, Air, and Soil Pollution, 127, pp. 351-372, 2001.

[13] Yu, Y., Xia, D.S., Chen, L.H., Liu, N., Chen, J.B. \& Gao, Y.H., Analysis of particulate pollution characteristics and its causes in Lanzhou, Northwest China. Environmental Science, 31(1), pp. 22-28, 2010.

[14] Wei, F., Teng, E., Wu, G., Hu, W., Wilson, W. E., Chapman, R. S., Pau, J. C. \& Zhang, J., Ambient concentrations and elemental compositions of $\mathrm{PM}_{10}$ and $\mathrm{PM}_{2.5}$ in four Chinese cities. Environmental Science \& Technology, 33(23), pp. 4188-4193, 1999.

[15] Wang, SG, Feng, X.Y., Zeng, X.Q., Ma, Y.X. \& Shang, K.Z., A study on variations of concentrations of particulate matter with different sizes in Lanzhou, China. Atmospheric Environment, 43(17), pp. 2823-2828, 2009.

[16] Wang, X., Xi, X.X., Guo, Z.L., Liu, Z.G. \& Chen, X.L., Analysis of the sand-stormy weather in Lanzhou during the spring of 2002. Journal of Lanzhou University, 42(3), pp. 44-47, 2006.

[17] Beddows, D.C .S, Dall'osto, M. \& Harrison, R.M., Cluster Analysis of Rural, Urban, and Curbside Atmospheric Particle Size Data. Environmental Science \& Technology, 43, pp. 4694-4700, 2009.

[18] Zhang, T., Tao, J., Wang, B. G. \& Zhang, R.J., Research on size distribution of particles and its impact on visibility in urban Guangzhou during spring. Journal of the Graduate School of the Chinese Academy of Sciences, 27( 3), pp. 331-337, 2010.

[19] Gao, J., Wang, J., Cheng, S.H., Yang, L.X., Wang, W.X. \& Wang, T., Studies on characteristics of size distribution and formation mechanism of fine particle matters in Summer of Ji'nan. Journal of the Graduate School of the Chinese Academy of Sciences, 24(5), pp. 680-687, 2007.

[20] Chen, Y.Z., Chai, F.H. \& Wei, Q., Study on size distribution of aerosol composition in winter in Beijing. Journal of Safety and Environment, 6(1), pp. 80-84, 2006.

[21] Yan, W.L., Zhou, D.P., Wang, Y.F., Yang, J. \& Li, Z.H., Concentrations and Size Distributions of Inhalable Particles in Summer and Winter in Shenyang. Journal of Applied Meteorological Science, 19(4), pp. 435443, 2008. 
[22] Morawska, L., Thomas, S., Jamriska, M. \& Johnson, G., The modality of particle size distributions of environmental aerosols. Atmospheric Environment, 33, pp. 4401-4411, 1999.

[23] Zhang, X.Y., Gong, S.L., Shen, Z.X., Mei, F.M., Xi X.X., Liu, L.C., Zhou, Z.J., Wang, D., Wang, Y.Q. \& Cheng, Y., Characterization of soil dust aerosol in China and its transport/distribution during 2001 ACEAsia, 1. Network observations. Journal of Geophysical Research, 108, pp. 4261, doi: 10.1029/2002JD002633, 2003. 